\title{
Enzymatic surface hydrolysis of poly(ethylene terephthalate) and bis(benzoyloxyethyl) terephthalate by lipase and cutinase in the presence of surface active molecules
}

\author{
Anita Eberl ${ }^{\mathrm{a}, \mathrm{b}}$, Sonja Heumann ${ }^{\mathrm{a}, \mathrm{b}}$, Tina Brückner ${ }^{\mathrm{a}, \mathrm{c}}$, Rita Araujo ${ }^{\mathrm{d}}$, Artur Cavaco-Paulo ${ }^{\mathrm{d}}$, \\ Franz Kaufmann ${ }^{\mathrm{e}}$, Wolfgang Kroutil ${ }^{\mathrm{a}, \mathrm{f}}$, Georg M. Guebitz ${ }^{\mathrm{a}, \mathrm{b}, *}$ \\ ${ }^{a}$ Research Centre Applied Biocatalysis, Petersgasse 14, A-8010 Graz, Austria \\ b Graz University of Technology, Department of Environmental Biotechnology, Petersgasse 12, A-8010 Graz, Austria \\ c Niederrhein, University of Applied Sciences, Department of Textile and Clothing Technology, 41065 Mönchengladbach, Germany \\ d University of Minho, Textile Engineering Department, 4800-058 Guimarães, Portugal \\ e CIBA Inc., Basel, Switzerland \\ ${ }^{\mathrm{f}}$ Department of Chemistry, Organic and Bioorganic Chemistry, University of Graz, Austria
}

\section{A R T I C L E I N F O}

\section{Article history:}

Received 2 February 2009

Received in revised form 3 July 2009

Accepted 10 July 2009

Keywords:

Poly(ethylene terephthalate)

Surface modification

Polyesterase

\begin{abstract}
A B S T R A C T
A lipase from Thermomyces lanuginosus and cutinases from Thermobifida fusca and Fusarium solani hydrolysed poly(ethylene terephthalate) (PET) fabrics and films and bis(benzoyloxyethyl) terephthalate (3PET) endo-wise as shown by MALDI-Tof-MS, LC-UVD/MS, cationic dyeing and XPS analysis. Due to interfacial activation of the lipase in the presence of Triton X-100, a seven-fold increase of hydrolysis products released from 3PET was measured. In the presence of the plasticizer $N, N$-diethyl-2-phenylacetamide (DEPA), increased hydrolysis rates of semi-crystalline PET films and fabrics were measured both for lipase and cutinase. The formation of novel polar groups resulted in enhanced dye ability with additional increase in colour depth by $130 \%$ and $300 \%$ for cutinase and lipase, respectively, in the presence of plasticizer.
\end{abstract}

(c) 2009 Elsevier B.V. All rights reserved.

\section{Introduction}

In the last few years there has been increasing interest in enzymatic surface modification of poly(ethylene terephthalate) (PET) (Fischer-Colbrie et al., 2007; Heumann et al., 2006; Eberl et al., 2008; Guebitz and Cavaco-Paulo, 2008; Alisch et al., 2004; Vertommen et al., 2005; Alisch-Mark et al., 2006; Silva et al., 2007; Kim and Song, 2006; Liu et al., 2008) which is widely used in the textile industry with an annual production of 36 million tons (CIRFS, 2008; Guebitz and Cavaco-Paulo, 2008). Besides excellent physico-chemical properties of polyesters increased hydrophilicity is essential for many applications ranging from textiles to medical and electronics (Guebitz and Cavaco-Paulo, 2008). Conventionally, alkaline treatment is used to increase hydrophilicity of PET based textile materials (Zeronian and Collins, 1989; Hsieh et al., 1996). However, formation of pit-like structures (Brückner et al., 2008) results in high weight loss and leads to reduced fibre strength. Enzymes like lipases and cutinases only result in superficial formation of hydroxyl and carboxyl groups because diffusion

\footnotetext{
* Corresponding author at: Graz University of Technology, Department of Environmental Biotechnology, Petersgasse 12, A-8010 Graz, Austria.

E-mail address: guebitz@tugraz.at (G.M. Guebitz).
}

into the fibres is not expected due to their size (Brückner et al., 2008). In contrast, during alkaline treatment PET is successively degraded from the chain ends. While the enzymatic surface hydrolysis holds great potential, long incubation times are the limiting factor but at the same time enzyme-substrate interactions have not been investigated in enough detail. In most previous studies, changes of PET surface properties like hydrophilicity, dye-binding or depilling have been correlated to the release of terephthalic acid or short oligomers (Guebitz and Cavaco-Paulo, 2008) while chemical changes on the polymer have been rarely assessed. Thus, in this study for the first time, MALDI-Tof-MS was used simultaneously with XPS to study polymer surface chemistry and LC-UVD/MS to analyse for smaller reaction products to study the hydrolysis mechanism of cutinases and lipases on PET (i.e. endo- versus exo-type of hydrolysis).

Lipases are generally known to catalyze the hydrolysis of long chain water insoluble triglycerides. In the presence of a water-lipid interface the phenomenon of "interfacial activation" is characteristic for this class of enzymes while cutinases do not show such behaviour (Grochulski et al., 1993; Pleiss et al., 1998; Fojan et al., 2000). Lipases have an additional small peptide segment, referred to as a lid, which covers the pocket of the active site. In the open, active form of the lipase, the active site becomes accessible to the substrate. 
It has previously been indicated that the dyeing behaviour of textiles can be improved by lipase in the presence of detergents (Kim and Song, 2006). For the lipase from Thermomyces lanuginosus investigated in this study, activation by detergents resulting in dramatically enhanced hydrolysis on p-nitrophenyl butyrate has been reported (Mogensen et al., 2005). In this study, we investigated whether a similar influence of the non-ionic detergent Triton X-100 exists for enzymatic (surface) hydrolysis PET and bis(benzoyloxyethyl) terephthalate (3PET (Heumann et al., 2006)).

Plasticizers are conventionally applied in finishing processes for polyester fabrics to decrease glass transition temperature and to increase the access to amorphous parts of the fibres at lower temperatures. It is known that enzymes preferentially attack the amorphous regions of polymers (Herzog et al., 2006; Donelli et al., 2009; Müller et al., 2005; Vertommen et al., 2005). Since enzymatic treatments are usually performed at up to $60^{\circ} \mathrm{C}$, which is below the glass transition temperature of $-80^{\circ} \mathrm{C}$ (Kaiserberger et al., 1993) the addition of plasticizers could enhance the efficiency of enzymes by increasing the chain mobility of the polymers. Hence the influence of plasticizers on the enzyme-polymer interaction was also investigated.

\section{Materials and methods}

\subsection{Chemicals and enzymes}

\subsubsection{Chemicals}

Methanol and acetonitrile used were HPLC grade quality and purchased from Roth (Carl Roth GmbH, Karlsruhe, Germany) and VWR Prolabo, respectively. Water used was double deionised. Astrazone Blue BG (C.I. Basic Blue 3, purity 98\%) was a kind gift of Dystar Textilfarben (Frankfurt, Germany). All other chemicals were analytical grade from SIGMA.

\subsubsection{Enzymes}

The cutinases from Fusarium solani pisi and Thermobifida fusca were produced as previously described (Müller et al., 2005; Araujo et al., 2007). The cutinase from T. fusca was stored as lyophilised powder with a protein content of $5 \%$ while the $F$. solani pisi was stored as buffered solution at $4{ }^{\circ} \mathrm{C}$. The lipase from $T$. lanuginosus is available from Novozymes. The protein content of enzyme solutions was measured according to the method of Lowry (Lowry et al., 1951). Based on previous investigations (Brückner et al., 2008) the cutinases from T. fusca and F. solani and the lipase from T. lanuginosus were used in concentrations of $0.2 \mathrm{~g}, 1.5 \mathrm{~g}$ and $19 \mathrm{~g}$ protein $\mathrm{L}^{-1}$, respectively, in $50 \mathrm{mM}$ phosphate buffer, $\mathrm{pH} 7\left(\mathrm{Na}_{2} \mathrm{HPO}_{4} / \mathrm{KH}_{2} \mathrm{PO}_{4}\right)$.

\subsection{Substrates}

For activity measurements the water insoluble PET model substrate bis(benzoyloxyethyl) terephthalate (3PET) was used. Synthesis and purification were described previously (Heumann et al., 2006; Fischer-Colbrie et al., 2004). Additionally, bis(2hydroxyethyl) terephthalate (BHET) was employed to study enzyme activity on a water soluble substrate. Oligomeric PET $\left(M_{\mathrm{W}}=3500\right)$ was from Polymer Standards Service GmbH (PSS, Mainz, Germany).

Poly(ethylene terephthalate) fabrics were obtained from InoTEX (Dvur Kralove, Czech Republic). The fabrics were plain-woven with a mass per unit area of $177 \mathrm{~g} / \mathrm{m}^{2}$. PET films were kindly supplied by Mitsubishi Polyester Film (Wiesbaden, Germany). Two different films with a thickness of $75 \mu \mathrm{m}$ were used i.e. Hostaphan RNK 75 (semi-crystalline), and Hostaphan RHS 75. Hostaphan RHS 75 consists of a double layer with one amorphous layer due to copolymerisation with isophthalic acid and a second layer with the same composition as the RNK film.
The degree of crystallinity of the polymers was determined by Differential Scanning Calorimetry (DSC) runs and calculated to be about $40 \%$ for PET fabric and $27 \%$ for RNK film. The actual degree of crystallinity of the amorphous layer of the RHS film could not be calculated, but the overall degree of crystallinity was $23 \%$. The heat of melting of a $100 \%$ crystalline PET polymer was accounted for $140 \mathrm{Jg}^{-1}$ (Kaiserberger et al., 1993). Crystallinity analysis for all polymeric substrates was carried out using a Perkin Elmer PYRIS DIAMOND DSC. Measurements were carried out as described previously (Eberl et al., 2008).

\subsection{Analysis of PET hydrolysis products}

\subsubsection{Sample preparation}

For enzyme activity assays $10 \mathrm{mg}$ of the purified model substrate 3PET were incubated in a $2 \mathrm{~mL}$ Eppendorf tube with $0.5 \mathrm{~mL}$ of appropriately diluted enzyme solution (protein concentrations see above). For BHET degradation a $0.5 \mathrm{mM}$ solution was prepared in $50 \mathrm{mM}$ phosphate buffer, $\mathrm{pH} 7\left(\mathrm{Na}_{2} \mathrm{HPO}_{4} / \mathrm{KH}_{2} \mathrm{PO}_{4}\right) .500 \mu \mathrm{L}$ of the BHET solution was mixed with $500 \mu \mathrm{L}$ enzyme solution and incubated at the according temperature for different incubation times. For PET-3500 $2 \mathrm{mg}$ was weighed into Eppendorf tubes for the treatments.

For polymer treatment three pieces of PET films or fabrics $(10 \mathrm{~mm} \times 5 \mathrm{~mm})$ were incubated in $2 \mathrm{~mL}$ Eppendorf tubes with $0.5 \mathrm{~mL}$ of the appropriately diluted enzyme solution for $120 \mathrm{~h}$. Additionally, the influence of the non-ionic detergent Triton X-100 $(0.1 \%$, $\mathrm{v} / \mathrm{v}$ ) and the plasticizer $N, N$-diethyl-2-phenylacetamide (DEPA, $1 \%$, $\mathrm{v} / \mathrm{v}$ ) was investigated. Incubation with the cutinase from T. fusca was carried out at $60^{\circ} \mathrm{C}$ at $450 \mathrm{rpm}$ (thermomixer comfort, Eppendorf); treatments with the cutinase from $F$. solani and the lipase from $T$. lanuginosus were done at $37^{\circ} \mathrm{C}$. After incubation the samples were put on ice to stop the reaction. For protein precipitation the samples for HPLC measurement were treated 1:1(v/v) with methanol abs. on ice. After $15 \mathrm{~min}$, the samples were centrifuged at 16,000 $\times \mathrm{g}$ for $15 \mathrm{~min}$ at $0^{\circ} \mathrm{C}$ (Hettich MIKRO $200 \mathrm{R}$, Tuttlingen, Germany). The supernatant was transferred to a HPLC vial and acidified by addition of $1 \mu \mathrm{L}$ of $\mathrm{HCl}$ conc.

For surface analysis experiments polymer pieces of $4 \mathrm{~cm} \times 4 \mathrm{~cm}$ were incubated in $15 \mathrm{~mL}$ of enzyme solution (protein concentrations see above) as described above for $120 \mathrm{~h}$. After the treatment polymer pieces were washed with Triton X-100 $\left(5 \mathrm{gL}^{-1}\right)$ and subsequently with $\mathrm{Na}_{2} \mathrm{CO}_{3}\left(2 \mathrm{~g} \mathrm{~L}^{-1}\right)$ for $30 \mathrm{~min}$ at $50^{\circ} \mathrm{C}$, further with deionised water ( $30 \mathrm{~min}$ ) and additionally soxhlet extracted overnight with ethanol and rinsed in pure water to remove adsorbed protein.

Blank incubations were also carried out with the substrates in the same buffer without enzyme addition as well as with the enzyme solutions only and accounted for in all calculations.

\subsubsection{HPLC-UV and mass spectrometric detection}

The HPLC equipment used was a DIONEX P-580 PUMP (Dionex Cooperation, Sunnyvale, USA), with an ASI-100 automated sample injector and a PDA-100 photodiode array detector. The MS spectra were acquired with an Agilent Ion Trap SL with electrospray ionisation which was coupled to the Dionex HPLC-PDA-system.

A reversed phase column RP-C18 (Eurospher 100-5, C18, $150 \mathrm{~mm} \times 4.6 \mathrm{~mm}$ with precolumn, Knauer $\mathrm{GmbH}$, Berlin, Germany) was used. Analysis was carried out with $20 \%$ acetonitrile, $20 \% 10 \mathrm{mM}$ sulphuric acid and $60 \%(\mathrm{v} / \mathrm{v})$ water as eluent at a wavelength of $241 \mathrm{~nm}$. The flow rate was set to $1 \mathrm{~mL} \mathrm{~min}^{-1}$ and the column was maintained at a temperature of $25^{\circ} \mathrm{C}$. The injection volume was $10 \mu \mathrm{L}$. For mass spectrometric detection positive ion mode as well as negative ion mode were used with an electrospray voltage of $-3500 \mathrm{~V}$ and $+3500 \mathrm{~V}$, respectively. Dry gas flow was set to $12 \mathrm{~L} \mathrm{~min}^{-1}$ with a temperature of $350^{\circ} \mathrm{C}$, nebulizer to $70 \mathrm{psi}$. 
Maximal accumulation time was fixed to $300 \mathrm{~ms}$ and the loading of the trap was controlled by the instrument with an ICC of 30,000.

Reference substances for terephthalic acid (TA), bis(2hydroxyethyl)terephthalate (BHET) and benzoic acid (BA) are commercially available.

\subsubsection{Matrix-assisted laser desorption ionisation (MALDI)}

After incubation of PET-3500 with enzymes, the samples were centrifuged, the enzyme solution removed and the residual PET-3500 air-dried. The dry powder was dissolved in $0.5 \mathrm{~mL}$ hexafluoroisopropanol (HFIP)/ $\mathrm{CH}_{2} \mathrm{Cl}_{2}$ (30:70, v:v). Dithranol was used as matrix in a concentration of $5 \mathrm{mg} \mathrm{mL}^{-1}$ and NaTFA was prepared at a concentration of $0.1 \mathrm{mg} \mathrm{mL}^{-1}$. The solutions were mixed in a ratio of $1: 1: 1$ and $1 \mu \mathrm{L}$ of the sample mixture was spotted onto a stainless steel target MALDI plate and air-dried before analysis in the mass spectrometer. Identification of the cleavage products was performed on a matrix-assisted laser desorption ionization reflectron-type time-of-flight (MALDI-Tof) mass spectrometer (Waters ${ }^{\circledR}$ Micromass ${ }^{\circledR}$ MALDI micro MX, Manchester, UK) equipped with a $337 \mathrm{~nm}$ nitrogen laser. Spectra were acquired in the reflectron positive mode and calibration was carried out using a mixture of PEG oligomers.

\subsection{Surface analysis}

\subsubsection{X-ray photoelectron spectroscopy (XPS)}

The modification in surface elemental composition was determined by X-ray photoelectron spectroscopy (XPS). The measurements were performed with an Omicron "Multiprobe" surface analysis system using $150 \mathrm{~W}$ monochromatized $\mathrm{Al} \mathrm{K}_{\alpha 1}$ radiation $(1486.70 \mathrm{eV}$, energy width $<300 \mathrm{meV})$. Photoelectrons were detected by an Omicron EA125 hemispherical electron analyser. The base pressure in the analysis chamber was $5 \times 10^{-11}$ mbar. The information depth of analysis was approximately $4 \mathrm{~nm}$.

\subsubsection{Dyeing and colour measurements}

Dyeing was carried out with basic dye Astrazon Blue BG (C.I. Basic Blue 3). A dyestuff solution of $0.05 \%(w / v)$ with deionised water was prepared and enzymatically treated PET fabrics were dyed for $10 \mathrm{~min}$ at room temperature on a rotary shaker at $40 \mathrm{rpm}$. Thereafter samples were rinsed thoroughly with deionised water and dried. Colour measurements were carried out on a Spectraflash ST 600 Plus (Datacolor International) with a wavelength range of $380-700 \mathrm{~nm}$. For characterisation of the dyed samples reflectance measurements were carried out five-fold and $\mathrm{K} / \mathrm{S}$ values compared at the wavelength of $660 \mathrm{~nm}$.

\section{Results and discussion}

In a first stage, enzymatic hydrolysis was studied using the PET model substrate bis(benzoyloxyethyl) terephthalate (3PET) monitoring hydrolysis products by using RP-HPLC-MS. Terephthalic acid (TA), bis(2-hydroxyethyl) terephthalate (BHET) and benzoic acid (BA) were identified based on reference molecules while in addition mono(2-hydroxyethyl) terephthalate (MHET) $\left(t_{\mathrm{r}}=5,6 \mathrm{~min}\right.$, $m / z=210)$ and 2-hydroxyethyl-benzoate (HEB) $\left(t_{\mathrm{r}}=13,033 \mathrm{~min}\right.$, $m / z=166$ ) were identified as hydrolysis products by MS (Fig. 1).

The chemical structure of this water insoluble PET model substrate is very similar to the PET polymers while enzymatic hydrolysis is much faster. However, a correlation was previously found between the hydrolytic activity of various polyesterases on the model substrate and on PET fabrics (Heumann et al., 2006). Incubation of 3PET with the cutinase from $T$. fusca resulted in an almost linear increase in the concentration of terephthalic acid (TA), mono(2-hydroxyethyl) terephthalate (MHET), bis(2-hydroxyethyl)

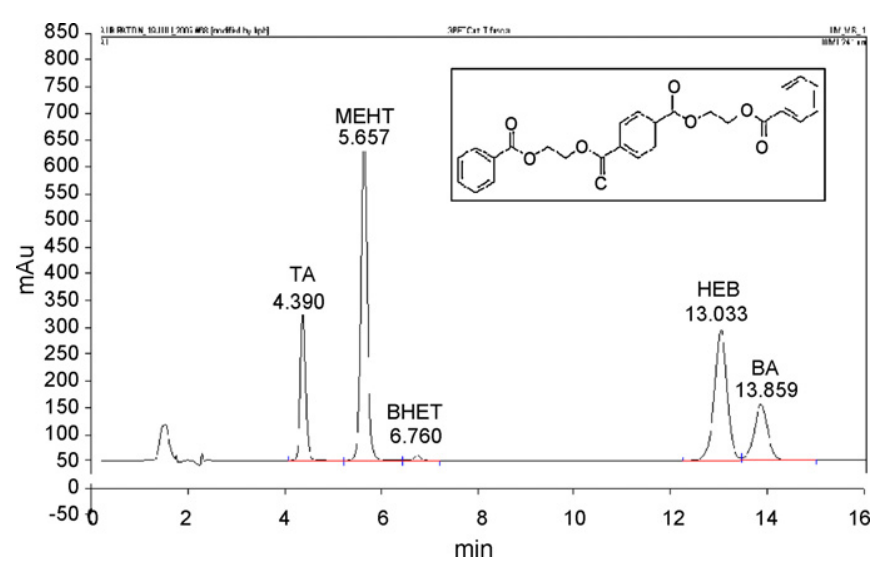

Fig. 1. Hydrolysis of 3PET with a cutinase from T. fusca: HPLC-UVD chromatogram at $241 \mathrm{~nm}$.

terephthalate (BHET), benzoic acid (BA) and 2-hydroxyethylbenzoate (HEB) within the first $5 \mathrm{~h}$ of incubation (Fig. 2).

After $24 \mathrm{~h}$ of incubation of 3PET with T. fusca cutinase the ratio of BA to HEB changed towards increasing amounts of BA indicating the ability of this enzyme to hydrolyse HEB. The cutinase from $F$. solani pisi showed a similar hydrolysis profile. Released HEB disappeared completely after $24 \mathrm{~h}$ of incubation. Additionally, the ratio of TA to MHET increased again. In contrast, this behaviour was not observed for the lipase where the ratio of BA to HEB always remained constant (up to one week of incubation) indicating that HEB cannot be hydrolysed by this enzyme. Similar properties were previously found for a polyesterase from Penicillium citrinum (Liebminger et al., 2007).

In a second step, the influence of the non-ionic detergent Triton $\mathrm{X}-100$ on the enzymatic hydrolysis of 3PET was investigated. A significant increase of hydrolysis products was observed using lipase from T. lanuginosus in presence of $0.1 \%(\mathrm{v} / \mathrm{v}$ ) Triton X-100 (Fig. 3). As with natural lipase substrates (Grochulski et al., 1993; Pleiss et al., 1998), conformational changes with lid-opening (enhanced by detergents) also seem to play an important role in 3PET hydrolysis as indicated by the seven-fold increase in overall degradation products. As expected, for the cutinases from $T$. fusca and $F$. solani pisi no activation was seen in the presence of Triton X-100 due to the absence of a lid covering the active site pocket. Even a deactivation of hydrolytic activity was observed, which leads to the assumption that this non-ionic detergent actually inhibits or destabilizes cutinases.

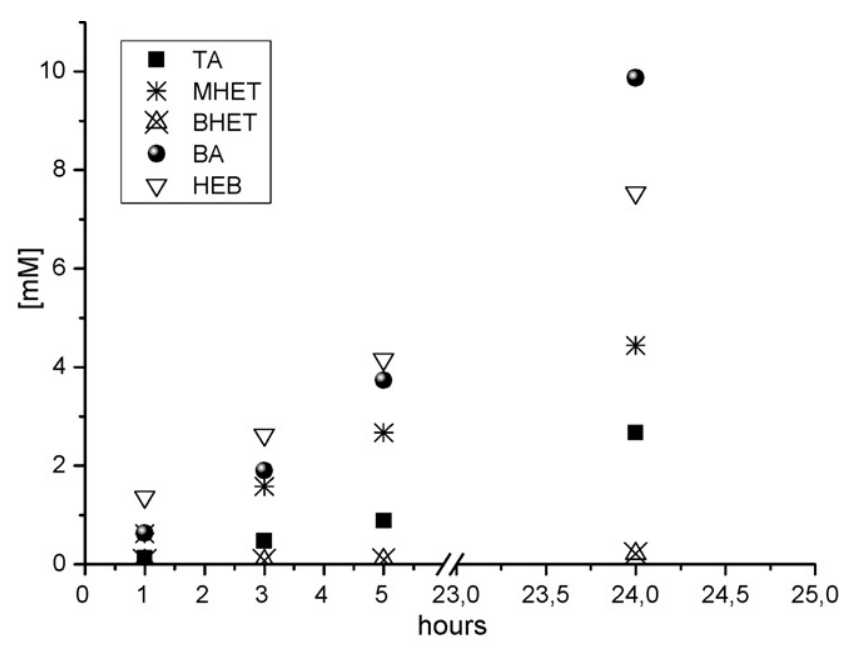

Fig. 2. Hydrolysis of 3PET with a cutinase from T. fusca. 


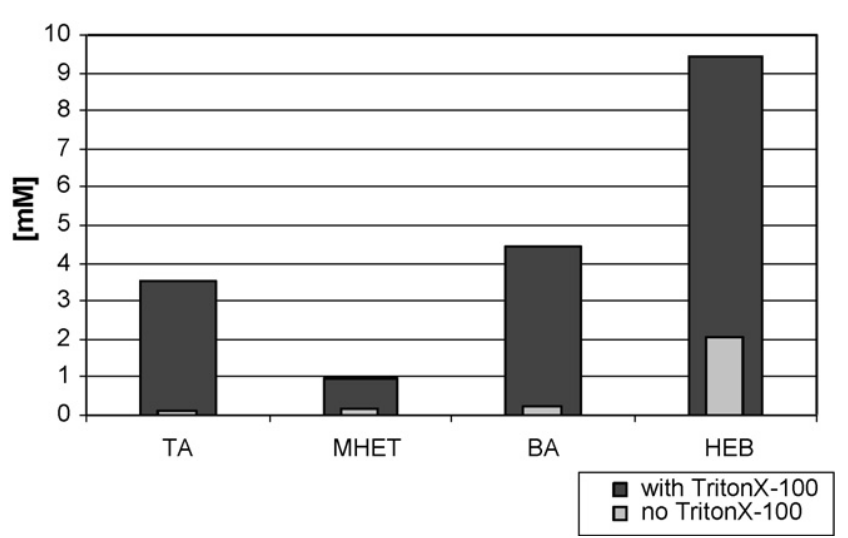

Fig. 3. Hydrolysis of 3PET with a lipase from T. lanuginosus for $24 \mathrm{~h}$.

Enzymatic hydrolysis of bis(2-hydroxyethyl terephthalate) (BHET) provides additional insight in the different hydrolysis mechanisms of cutinases and lipases. Both cutinases hydrolysed BHET rather fast with no BHET left after treatment for $30 \mathrm{~min}$ (F. solani) cutinase and after $5 \mathrm{~h}$ ( $T$. fusca), respectively. These experiments confirm the ability of cutinases to cleave ester bonds of dissolved materials (Müller et al., 2005; Kleeberg et al., 2005). Interestingly, formation of TA by the cutinases did not start before complete hydrolysis of BHET to the mono-ester. A similar effect was previously observed for enzymatic hydrolysis of diethylene glycol terephthalate (DTP) (Zhang et al., 2004). In contrast, within the same incubation time the lipase from $T$. lanuginosus did not liberate significant amounts of TA. On the other hand, this released TA from 3PET. This indicates, that the enzyme has a preference to release TA from the larger hydrolysis product of 3PET namely mono(benzoyloxyethyl) terephthalate when compared to BHET.

We and other authors have previously shown that polyesterases preferably attack amorphous parts of PET (Herzog et al., 2006; Vertommen et al., 2005; Brückner et al., 2008). Recently, an increase of the crystalline moieties of PET after enzyme treatment was demonstrated by using FTIR-ATR (Donelli et al., 2009). Therefore, the effect of plasticizers on the enzymatic hydrolysis of the polymer was investigated in this study. Plasticizers reduce the glass transition temperature and inter chain interaction resulting in enhanced chain mobility. Consequently, a considerable increase in the amount of the hydrolysis products TA and MHET released from the PET fabric and from the semi-crystalline film RNK was measured for both, the T. lanuginosus lipase and the T. fusca cutinase in presence of the plasticizer $N, N$-diethylphenyl acetamide (DEPA) at $1 \%(v / v)$ (Fig. 4$)$. We assume that the outer layers of the polymer will be better exposed to the enzyme in the presence of DEPA. On the other hand, DEPA



Fig. 4. Influence of the plasticizer DEPA $(N, N$-diethyl-2-phenylacetamide) on hydrolysis of semi-crystalline PET (Hostaphan RNK 75) with a lipase from T. lanuginosus and a cutinase from T. fusca.


Fig. 5. MALDI-Tof-MS analysis of PET $\left(M_{\mathrm{W}}=3500\right)(\mathrm{A})$ and comparison of selected fragments resulting after partial hydrolysis with a lipase from $T$. lanuginosus and a cutinase from T. fusca (B) compared to an untreated control. All fragment ions represent $\mathrm{Na}^{+}$adducts.

might also have an influence on the enzyme, which, however was not seen for small substrates (data not shown). For the T. lanuginosus lipase, no hydrolytic activity on the film was found without plasticizer, but there was some activity on the fabric. In the presence of the plasticizer, a significant increase of degradation products was measured for both enzymes, whereby the effect was even higher on the fabrics. The striking distinction of released hydrolysis products between film and fabric can be referred to the higher actual surface area accessible for the fabrics (Eberl et al., 2008). From RHS film consisting of one amorphous sealing layer, lower amounts of degradation products were released by adding DEPA compared to the control. However, not the release of small water soluble hydrolysis products is the main goal of enzymatic PET hydrolysis, but rather an increase of surface hydrophilic properties is important which is due to endo-wise hydrolysis of the backbone of the polymer chain. Thus, the mechanism of hydrolysis for cutinase and lipase was studied in more detail.

MALDI-Tof-MS analysis indicated an endo-type enzymatic hydrolysis of PET $\left(M_{\mathrm{W}}=3500\right)$. However, there is some preference of the enzyme to act repeatedly on the same polymer chain as indicated by higher amounts of smaller fragments (e.g. $\mathrm{m} / z$ 854) compared to larger fragments $(m / z$ 1623). This effect was more pronounced for the lipase (Fig. 5). These results are in agreement with XPS data of this study (Fig. 6). For enzymatically treated PET the relative amount of hydroxyl groups $(\mathrm{C}-\mathrm{OH}$ at $286 \mathrm{eV})$ and free acid groups $(\mathrm{HO}-\mathrm{C}=\mathrm{O}$ at $290 \mathrm{eV}$ ) increased at the expense of $\mathrm{C}-\mathrm{C}$ bonds at $285 \mathrm{eV}$. Free acid groups were only detected in the enzyme treated samples. Slightly higher amounts of novel hydroxyl groups were formed by the lipase which is in line with the MALDI-Tof-MS results. The peak at $289 \mathrm{eV}$ corresponds to the ester bonds in the polymer while the small increase could be due to the preference 


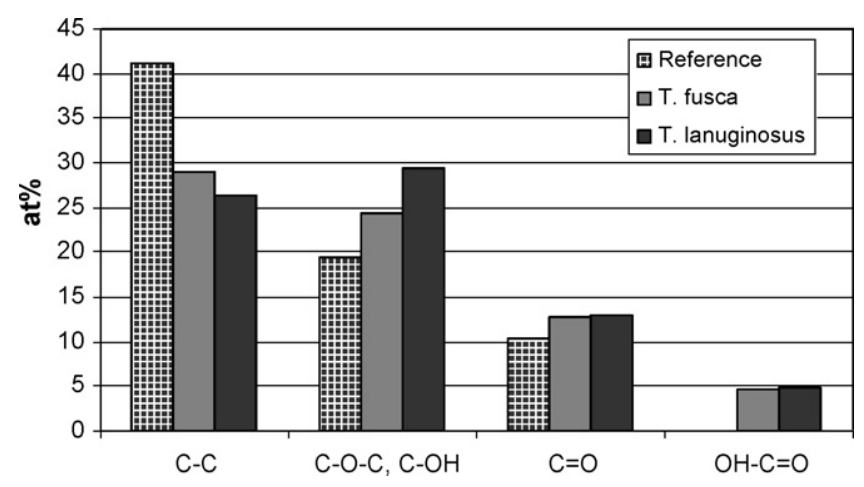

Fig. 6. Surface composition of PET partially hydrolysed with a lipase from $T$. lanuginosus and a cutinase from T. fusca: Atom percent of different C1s-binding types from XPS analysis ( $\mathrm{C}-\mathrm{C} \sim 285 \mathrm{eV}$; $\mathrm{C}-\mathrm{O}-\mathrm{C}, \mathrm{C}-\mathrm{OH} \sim 286 \mathrm{eV} ; \mathrm{C}=\mathrm{O} \sim 289 \mathrm{eV}$; $\mathrm{OH}-\mathrm{C}=\mathrm{O} \sim 290 \mathrm{eV})$.

of the enzyme to release terminal TA rather than EG from novel chain ends. This is in agreement with previous results for chemical hydrolysis of PET (Brückner et al., 2008).

Finally, the effect of enzyme treatment in presence and absence of surface active molecules on the surface properties of PET was examined by basic dyeing. Adsorption of proteins to the polymer can provoke hydrophilicity increases (Vertommen et al., 2005), hence an efficient washing procedure after enzyme treatment was used. Complete removal of proteins from treated fabrics could finally be achieved according to XPS analysis (Brückner et al., 2008) since no nitrogen peak (binding energy $400 \mathrm{eV}$ ) was apparent in the spectrum. A clear increase in colour shade of dyed PET was seen for both enzymes compared to the reference (Fig. 7). The slight colouring of the reference is derived from the presence of carboxylic end groups on the polymeric chain. In the presence of the plasticizer DEPA an increase of $\mathrm{K} / \mathrm{S}$ values of approx. $30 \%$ for the lipase and $40 \%$ for the cutinase was found. Compared to the reference an overall enhancement in colour depth of $300 \%$ was achieved with the T. fusca cutinase in the presence of DEPA. In contrast, the influence of Triton $\mathrm{X}-100$ on enzymatic hydrolysis of the polymer was lower regarding both increase of $\mathrm{K} / \mathrm{S}$ values and release of hydrolysis products.

Although there was a correlation between the amount of small hydrolysis products (TA and MHET) released and increase in colour shade was found (Fig. 7) different phenomena must be considered. Such correlation between released water soluble hydrolysis products and improved hydrophilicity and/or dyeing behaviour has been previously been reported by several authors for individual enzymes (Guebitz and Cavaco-Paulo, 2008). However, neither improved dye-

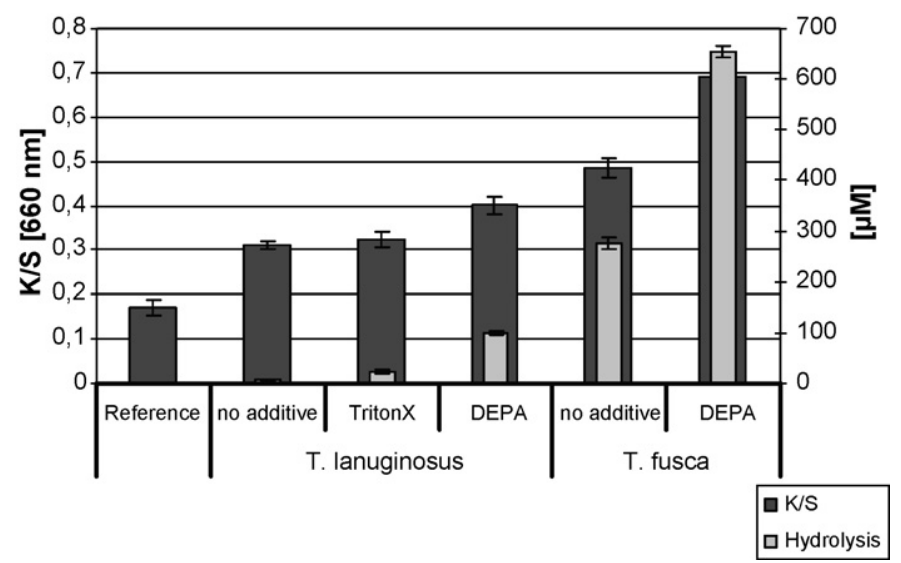

Fig. 7. K/S values of dyed PET fabrics pre-treated with a lipase from $T$. lanuginosus and a cutinase from T. fusca and total amount of hydrolysis products TA and MHET. ing behaviour nor hydrophilicity increases of PET are caused by enzymatic release of small water soluble products (TA or MHET). Only an endo-type enzymatic cleavage of PET will result in changes of the surface properties. Thus, this correlation factor should be different for each individual enzyme depending whether it is more endo- or exo-acting. Indeed, the T. fusca cutinase releases three times more small water soluble hydrolysis products than the $T$. lanuginosus lipase to reach a similar increase in $\mathrm{K} / \mathrm{S}$ values $(0.40$ versus 0.49) in basic dyeing (Fig. 7). Previously, such discrepancy has also been reported for hydrophilicity increases (Brückner et al., 2008). On the other hand, we demonstrated here for the first time using MALDI-Tof-MS that "polyesterases" show endo-type cleaving mechanism of PET while the lipase and cutinase showed similar characteristics. Also, XPS analysis had confirmed a similar increase in hydroxyl groups. Taken together this confirms our hypothesis that endo-type enzymatic hydrolysis is essential for surface functionalisation.

\section{Conclusions}

In this study, the positive influence of surface active molecules on enzymatic hydrolysis of PET and the oligomeric 3PET was demonstrated. A significant increase of hydrolysis products from the model substrate of PET was observed in the presence of nonionic detergent Triton X-100 for the T. lanuginosus lipase due to interfacial activation. As expected, this effect was not seen for the group of cutinases. On the other hand, addition of the plasticizer DEPA lead to enhanced hydrolysis rates for both, lipase and cutinase on semi-crystalline PET polymers (film and fabric). Consequently, the presence of DEPA and Triton X-100 lead to increased K/S values in basic dyeing of enzyme pretreated PET. Considering the potential of enzymatic PET functionalisation together with currently low reaction rates, further assessment of surface active molecules will be one step forward towards the optimization of this process. On the other hand, genetic engineering and screening to obtain more efficient polyesterases will only be possible with detailed mechanistic understanding. Here we have shown that polyesterases act endowise on PET cleaving PET $\left(M_{\mathrm{W}}=3500\right)$ randomly and thus creating new polar groups on the surface (XPS). According to MALDI-Tof-MS and XPS data, the lipase created slightly higher amounts of larger fragments from PET than the cutinase. On the other hand, the cutinase released more water soluble small fragments. This difference in the enzyme specificities is also reflected in the hydrolysis pattern of bis(benzoyloxyethyl) terephthalate (3PET) where the lipase does not hydrolyse HEB.

\section{Acknowledgements}

Many thanks to Ulrike Geweßler and Matthias Pretzler for lab work. The research was financed by the SFG, the FFG, the city of Graz and the province of Styria.

\section{References}

Alisch, M., Feuerhack, A., Muller, H., Mensak, B., Andreaus, J., Zimmermann, W., 2004. Biocatalytic modification of polyethylene terephthalate fibres by esterases from actinomycete isolates. Biocatal. Biotransform. 22, 347-351.

Alisch-Mark, M., Herrmann, A., Zimmermann, W., 2006. Increase of the hydrophilicity of polyethylene terephthalate fibres by hydrolases from Thermomonospora fusca and Fusarium solani F. sp.pisi. Biotechnol. Lett. 28, 681-685.

Araujo, R., Silva, C., O'Neill, A., Micaelo, N., Guebitz, G., Soares, C.M., Casal, M., CavacoPaulo, A., 2007. Tailoring cutinase activity towards polyethylene terephthalate and polyamide 6,6 fibers. J. Biotechnol. $128,849-857$.

Brückner, T., Eberl, A., Heumann, S., Rabe, M., Guebitz, G.M., 2008. Mechanistic study of enzymatic and chemical hydrolysis of poly(ethylene terephthalate). J. Polymer Sci. 46, 6435-6443.

CIRFS, 2008. International Rayon and Synthetic Fibres Committee. http://www. cirfs.org/. 
Donelli, M., Taddei, P., Smet, P.F., Poelman, D., Nierstrasz, V.A., Freddi, G., 2009 Enzymatic surface modification and functionalization of pet. In: A water contact angle, FTIR, and Fluorescence Spectroscopy Study, COST868 Conference, Istanbul, Turkey, February 19-20.

Eberl, A., Heumann, S., Kotek, R., Kaufmann, F., Mitsche, S., Cavaco-Paulo, A., Guebitz, G.M., 2008. Enzymatic hydrolysis of PTT polymers and oligomers. J. Biotechnol. $135,45-51$.

Fischer-Colbrie, G., Heumann, S., Liebminger, S., Almansa, E., Cavaco-Paulo, A., Guebitz, G.M., 2004. New enzymes with potential for PET surface modification. Biocatal. Biotransform. 22, 341-346.

Fischer-Colbrie, G., Matama, T., Heumann, S., Martinkova, L., Cavaco Paulo, A., Guebitz, G., 2007. Surface hydrolysis of polyacrylonitrile with nitrile hydrolysing enzymes from Micrococcus luteus BST20. J. Biotechnol. 129, 62-68.

Fojan, P., Jonson, P.H., Petersen, M.T.N., Petersen, S.B., 2000. What distinguishes an esterase from a lipase: a novel structural approach. Biochimie 82, 1033-1041.

Grochulski, P., Li, Y., Schrag, J.D., Bouthillier, F., Smith, P., Harrison, D., Cygler, M., 1993. Insights into interacial activation from an open structure for Candida rugosa lipase. J. Biol. Chem. 286, 12843-12847.

Guebitz, G.M., Cavaco-Paulo, A., 2008. Enzymes go big: surface hydrolysis and functionalisation of synthetic polymers. Trends Biotechnol. 26, 32-38.

Herzog, K., Müller, R.J., Deckwer, W.D., 2006. Mechanism and kinetics of the enzymatic hydrolysis of polyester nanoparticles by lipases. Polym. Degrad. Stab. 91, 2486-2498.

Heumann, S., Eberl, A., Pobeheim, H., Liebminger, S., Fischer-Colbrie, G., Almansa, E., Cavaco-Paulo, A., Gubitz, G.M., 2006. New model substrates for enzymes hydrolysing polyethylene terephthalate and polyamide fibres. J. Biochem. Biophys. Methods 69, 89-99.

Hsieh, Y.L., Miller, A., Thompson, J., 1996. Wetting, pore structure and liquid retention of hydrolyzed polyester fabrics. Text. Res. J. 66, 1-10.

Kaiserberger, E., Knappe, S., Möhler, H., 1993. Netzsch Annual for Science and Industry: TA for Polymer Engineering: DSC-TG-DMA. Netzsch, Burlington, USA
Kim, H.R., Song, W.S., 2006. Lipase treatment of polyester fabrics. Fibers Polym. 7 , 339-343.

Kleeberg, I., Welzel, K., VandenHeuvel, J., Müller, R.J., Deckwer, W.D., 2005. Characterization of a new extracellular hydrolase from Thermobifida fusca degrading aliphatic-aromatic copolyesters. Biomacromolecules 6, 262-270.

Liebminger, S., Eberl, A., Sousa, F., Heumann, S., Fischer-Colbrie, G., Cavaco-Paulo, A., Guebitz, G., 2007. Hydrolysis of PET and bis-(benzoyloxyethyl) terephthalate with a new polyesterase from Penicillium citrinum. Biocatal. Biotransform. 25 , 171-177.

Liu, Y.B., Wu, G.F., Gu, L.H., 2008. Enzymatic treatment of PET fabrics for improved hydrophilicity. AATCC Review 8, 44-48.

Lowry, O.H., Rosebrough, N.J., Farr, A.L., Randall, R.J., 1951. Protein measurement with the Folin phenol reagent. J. Biol. Chem. 193, 265-275.

Mogensen, J.E., Sehgal, P., Otzen, D.E., 2005. Activation, inhibition, and destabilization of Thermomyces lanuginosus lipase by detergents. Biochemistry 44, 1719-1730.

Müller, R.J., Schrader, H., Profe, J., Dresler, K., Deckwer, W.D., 2005. Enzymatic degradation of poly(ethylene terephthalate): rapid hydrolyse using a hydrolase from T. fusca. Macromol. Rapid Commun. 26, 1400-1405.

Pleiss, J., Fischer, M., Schmid, R.D., 1998. Anatomy of lipase binding sites: the scissile fatty acid binding site. Chem. Phys. Lipids 93, 67-80.

Silva, C., Araujo, R., Casal, M., Gubitz, G.M., Cavaco-Paulo, A., 2007. Influence of mechanical agitation on cutinases and protease activity towards polyamide substrates. Enzyme Microbiol. Technol. 40, 1678-1685.

Vertommen, M.A.M.E., Nierstrasz, V.A., Veer, M.v.d., Warmoeskerken, M.M.C.G., 2005. Enzymatic surface modification of poly(ethylene terephthalate).J. Biotechnol. 120, 376-386.

Zeronian, S.H., Collins, M.J., 1989. Surface modification of polyester by alkaline treat ments. Tex. Progr. 20, 1-34.

Zhang, J., Wang, X., Gong, J., Gu, Z., 2004. A study on the biodegradability of polyethylene terephthalate fiber and diethylene glycol terephthalate. J. Appl. Polym. Sci. 93, 1089-1096. 